\title{
Erratum to: Trends in Media Reports of Celebrities' Breast Cancer Treatment Decisions
}

\section{Michael S. Sabel, MD, FACS ${ }^{1}$ and Sonya Dal Cin, PhD $^{2}$}

${ }^{1}$ Department of Surgery, University of Michigan Health System, Ann Arbor, MI; ${ }^{2}$ Department of Communication Studies, University of Michigan, Ann Arbor, MI

ERRATUM TO: ANN SURG ONCOL (2016) 23:2795-2801 DOI 10.1245/S10434-016-5202-7

In the XML of the original article, Dr. Dal Cin's name was incorrectly tagged. It has been corrected with this erratum. 